\title{
Neue Käfer-Arten von Margellan (Turkestan) von
}

\section{Dr. G. $K r a a t z$}

1. Craspedonotus margellanicus Kraatz. Niger, antennarum scapo tibiisque testaceis, thoracis margine laterali haud dilatato, elytris humeris minus regulariter punctato-striatis. - Long. $18-20$ mill.

Der Käfer weicht von dem japanischen Craspedonotus tibialis Schaum (Berlin. Ent. Zeitschr. 1863. p. 87) sehr auffällig durch das ganz einfach gebildete Halsschild ohne erweiterte Seitenränder und die nur nach aufsen und unterhalb der Schulter weniger regelmäfsig punktirt getreiften Fld. ab, stimmt aber durch den hellgelben Fühlerschaft und die hellgelben Schienen in so auffallender Weise mit Craspedonotus überein, dafs mir kein Grund vorzuliegen scheint, ihn generisch von Craspedonotus zu trennen. Er ist gewölbter als die japanische Art, auch sind die Fühler und Fülse viel feiner. An den ersteren ist aufser Glied 1-3 nur die Hälfte des vierten Gliedes glatt, die hintere Hälfte den folgenden Gliedern ähnlich behaart; das erste Glied ist hellgelb. Der Kopf ist gewölbter als bei tibialis, im Uebrigen ziemlich analog gebaut, neben den Augen mit einer vertieften Linie, welche von einer erhabenen Längsbeule begrenzt ist. Die Punktirung ist fein und ziemlich verloschen. Der Thorax ist ähnlich wie bei Broscus gebaut, vor der Mitte gerundeter, hinter der Mitte stärker eingeschnürt; der Seitenrand bildet mit dem Hinterrand eine scharfe Ecke; oben ist er glatt, vor der Spitze mit einer winklig vertieften Linie und einem Längseindruck in der Mitte, an der Basis längsgestrichelt. Die Fld. zeigen fünfzehn regelmäfsige Punktstreifen; zwischen dem fünften und siebenten schiebt sich unterhalb der Schultern ein sechster ein, welcher bald verschwindet; aufserhalb des siebenten Streifs werden die Punktreihen viel undeutlieher. Die Unterseite ist gröfstentheils glatt, die Schienen sind hellgelb.

In Margellan in mehreren Ex. aufgefunden.

2. Scarites basiplicatus Heyden. S. saxicolae Bon. affinis, sed diversus primo intuitu insterstitiis elytrorum 5. 6. basi plicatis, striis 5. 6. 7. basi fortiter impressis.

Corpore magis lucido. Mandibulis fortioribus, magis arcuatis et acutis, medio fortius dentatis, fortiusque strigosis. Impressionibus thoracis. latioribus, evidentius longitudinaliter strigosis. Antennis 
eodem modo constructis, sed articulis ultimis minus deplanatis. Thorace antice perparum emarginato, ab angulis anticis obtuse dentiformibus ad angulos posticos acutius dentatos eodem modo rotundato, dein ad basin magis constricto, strictura longiore, basi medio emarginata; lineis impressis anticis, marginalibus et posticis lineaque mediana magis profundis, inde canaliculo circumcincto magis profundo; supra laevigato, punctis perparum minutis impressis, basi ad angulos posticos parum granulosa (in saxicola dense inaequaliter punctato, basi saepissime granulosa). Elytris minus parallelis, post humeros ampliatis, lucidis, laevigatis, extus solum granulatis (in saxicola opacis, densissime inaequaliter punctatis) striis $1-3$ a medio ad apicem evanescentibus, leviter striatopunctatis, ceteris magis punctatostriatis, a medio ad apicem subtilioribus; striis 5. 6. 7. fortiter impressis et interstitiis 5. 6. 7. obtuse fastigiato-plicatis, dente humerali magno acuto. Tibiis anticis dentibus acutissimis, inter dentem tertium et basin dente acuto unico (in saxicola $4-5$ denticulis minutis), tibiis intermediis extus fortiter sed non longe rubiginoso ciliatis (ita ut tibiae posticae) dentibus duobus magnis acutis. - Long. 27-31 mill.

Margellan et Samarkand in collectionibus v. Heyden et Kraatz nonnulla exemplaria.

3. Necrophorus nigerrimus Kraatz. Niger, antennarum clava, epistomo elytrorumque margine laterali concoloribus. - Long. 25 mill. ().

Den kleineren Ex. des Necr. morio gleich, aber von demselben durch die einfarbig schwarze Oberseite des Kopfes und die ebenso gefärbten umgeschlagenen Seitenränder des Halsschildes unterschieden. Fühler schwarz. Der Kopf ist hinter der eingedrückten Randlinie nur schwach punktirt; der eingeschlossene Raum ist durch eine vertiefte Linie zwischen den Augen in zwei ungleiche Hälften getheilt, von denen $\frac{2}{3}$ hinter der Linie, $\frac{1}{3}$ vor derselben liegt; dieser Theil ist ganz oben in keiner Weise vertieft, nur in der Mitte mit einer kaum vertieften Linie, vorn ganz glatt, hinten verloschen punktirt, wie der übrige Theil des Kopfes. Im Uebrigen ist der Käfer dem morio ähnlich, nur ist der umgebogene Seitenrand der Flügeldecken einfarbig schwarz.

Sämmtliche von mir untersuchten Stücke des germanicus und morio zeigten den Raum des Kopfes vor den Fühlern, glatt eingedrückt und rothgelb. Ein Weibchen von Margellan.

Cetonia conspersa Ball., var. confluens Krtz., und immarginata Krtz. siehe unter Käfer-Arten von Osch. 


\section{$2 \mathrm{BHL}$ Biodiversity Heritage Library}

Kraatz, G. 1884. "Neue Käfer-Arten von Margellan (Turkestan)." Deutsche entomologische Zeitschrift 1884(2), 229-230.

https://doi.org/10.1002/mmnd.48018840218.

View This Item Online: https://www.biodiversitylibrary.org/item/103412

DOI: https://doi.org/10.1002/mmnd.48018840218

Permalink: https://www.biodiversitylibrary.org/partpdf/235308

\section{Holding Institution}

Harvard University, Museum of Comparative Zoology, Ernst Mayr Library

\section{Sponsored by}

Harvard University, Museum of Comparative Zoology, Ernst Mayr Library

\section{Copyright \& Reuse}

Copyright Status: Public domain. The BHL considers that this work is no longer under copyright protection.

This document was created from content at the Biodiversity Heritage Library, the world's largest open access digital library for biodiversity literature and archives. Visit BHL at https://www.biodiversitylibrary.org. 